\title{
Construction of a remote laboratory aimed at augmenting knowledge on properties of materials.
}

\author{
Peter Arras \\ Department of engineering technology \\ Lessius University College \\ Mechelen, Belgium \\ Peter.arras@lessius.eu
}

\begin{abstract}
This paper will case study the construction of a remote laboratory for experimenting on the properties of materials. More specific, about the difference between material stiffness and shape stiffness of a construction.
\end{abstract}

Keywords- remote laboratory, material properties, distant learning

\section{INTRODUCTION}

Engineering and science students need practical work/laboratories to acquire the knowledge and practice in procedures they will have to use in their professional career. Both goals of the practical work need a different approach.

Is the practical work aimed at illustrating theories and concept presented in school course, than the outcome of the experiment is known and the practice should be constructed to fulfill all of goals of the course. [2] The experiment should be repeatable to the learner and aimed to find out about a specified concept or knowledge. It is more likely that students are more interested and motivated to experiment, and thus learn about the concept presented, rather than only study abstract concept in the course book.

If the practical work is aimed at acquiring procedural knowledge for professional use, the setup should be more lifelike and the learner should thoroughly prepare the experiment and process the results. The learner is motivated to do the experiments in knowing that this is similar to the procedures he will encounter while working in his professional career. [2]

From both viewpoints, it seems that practical work and experiments are important to students.

With the constraints in the provision of laboratories to students in mind, newer forms of laboratories and experimenting should be provided to offer enough experimenting opportunities to students. The constraints mentioned include lack of time, lack of laboratory space, mobility of students, specialized equipment.

This paper will case study the construction of a remote laboratory for experimenting on the properties of materials.
More specific, about the difference between material stiffness and shape stiffness of a construction.

Although simulation has its advantages (for dangerous and very expensive experiments), it does not provide the same feel as working in a real laboratory.[1]

In the remote laboratory the scientist (student) interactively uses a real physical experiment. The experiment can be in a different physical location of the operating technology and the technological component of the experiment must be accessible by telecommunication (i.e. over the internet).

\section{ROLE OF LABORATORY WORK IN LEARNING.}

Laboratory practice is important to engineering and science students, both for studying theoretical courses, as well as to prepare them for their professional career.

Specifically for studying effective laboratory activities should:

- Enable students to explicate and understand the questions they are investigating

- Enable students to decide what data is (ir)relevant

- Learn students the limitations of measurements, sampling and data

- Help students to make connections between science concepts and everyday phenomena

- Help students to apply mathematical reasoning and techniques to problems.

(adapted from ABET [4])

These ideas make it clear that the laboratory setup should give direction to students, and raise questions, but should not be an automated black box that will calculate all results, nor just present all the solutions. These are important characteristics we will bear in mind when constructing the remote laboratory. As such we will not automate measurements, nor let the web application calculate the results, but we will encourage the user to these tasks themselves. 


\section{CONSTRUCTION OF THE EXPERIMENT FOR THE REMOTE} LABORATORY:

\section{A. Difference between the remote laboratory and similar setups:}

- The interactive demonstration laboratory, is a laboratory in which students can observe in real time the experiments done in some other place. They can watch - by a camera observation - what is happening in the other lab, and can intervene by communicating with the scientist/teacher conducting the experiment. Communication can be online (telephone, Skype, videoconference) or offline (e-mail). This type of demonstration lab is suitable for big experiments, long lasting experiments and experiments which demand a lot of manual interactions. The interactive demonstration lab seems to be a natural way of enlarging the possibilities of a laboratory for using it with more students, and students who do not have the opportunity to use this or similar equipment for conducting the experiment at their home school or university. One of the major setbacks of this type of labs is the labor costs which are attached to conducting the experiments, and maintenance of the lab. Another difficult to control point is that students will have to be well prepared (topics studied, lab setup investigated) before attending the lab-session. If not well prepared, the lab session will be useless because students will have problems to understand what is happening. Valuable lab and labor (of the scientist/teacher) time will be spend without much efficiency when students are not prepared for the session.

- The virtual laboratory, in which students can experiment themselves with simulated experiments. Simulation means software made experiments. Although simulations or virtual laboratories can be also used to overcome the disadvantages of traditional laboratories, any simulation is simply a model of a physical process, which is just an approximation that cannot reproduce every aspect of the real phenomenon [3]. Some of the advantages of virtual laboratories are the availability of the experiments 24/24h, 7/7 days a week, the low cost of the experiment (the only cost is the computer cost, and development cost of the software experiment) and possibility to conduct (simulate) hazardous experiments. Since it is only virtual (software), no safety precautions have to be taken by the user, nor the provider of the experiment. Preparation of the experiment by the student is important, but is at their own expense: if students do not spend time preparing the experiment, they will lose time redoing the experiment to catch up with understanding the experiment.

- The remote laboratory is an automated laboratory (experiment) in which students can experiment to find out about the laws of nature of other phenomena. The access to the laboratory is over the internet, with no need for manual interference (in comparison with the interactive demonstration laboratory). In comparison with a virtual laboratory, the experiment in the remote lab is a real physical setup, not just a software simulation of an experiment. For pedagogical purposes the visualization and interactivity of the remote laboratory are among the most important features. Preparation of the experiment by the student is important, but is at their own expense as in the virtual laboratory. The preparation of students can be forced through the web-interface. E.g. students should first study the explanation about the laboratory and answer some questions on the theoretical background of the experiment, before being granted access to the experiment itself.

\section{B. Goal of the experiment on material properties.}

Stiffness of a construction is an important feature in (mechanical and construction design). Indeed, not only pure strength of the construction (resistance to rupture failure) is decisive for a construction, but often deformation of a design can undermine the usefulness and efficiency of the design. The characterization of the resistance to deformation is function of material parameters (material stiffness) and structural design parameters (shape stiffness). This difference is a difficult concept for pupils/students to understand, as we experienced over the years.

Because it is such an important and fundamental property of materials and construction, students should have the opportunity to experiment on this. With following 2 major thoughts in mind firstly, not enough time to do experiments hands on and secondly, the fact that the difference between material and structural stiffness is considered to be presumed knowledge to students entering higher education - it was decided to construct an automated lab to experiment on material and structural stiffness. The aim of the remote experiment is to show the difference between material and shape stiffness of a mechanical construction. It lets pupils/student experiment with different materials and shapes to study both components of structural stiffness.

\section{Methods used.}

To evaluate material stiffness we use a bending test setup. A cantilever beam is loaded with a known force. When measuring the deflection at the end of the beam we can calculate Young's modulus (for bending) of the material.

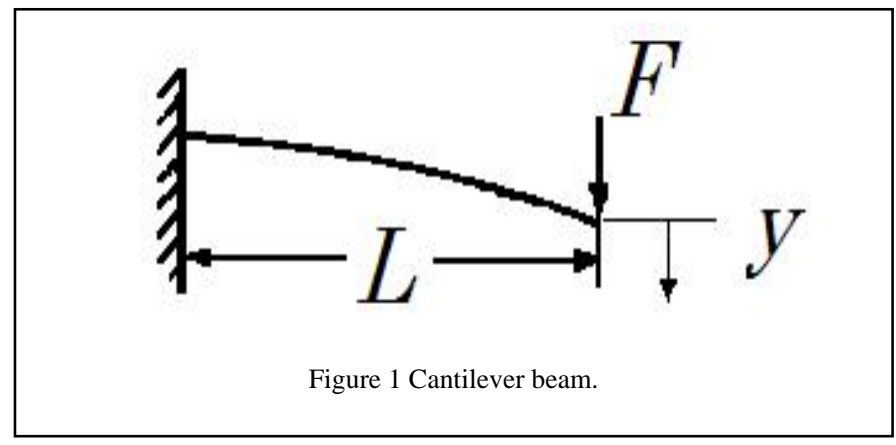

Deflection at the unsupported end:

$$
\mathrm{y}=\mathrm{F}^{*} \mathrm{~L} \wedge 3 /\left(3 * \mathrm{E}^{*} \mathrm{I}\right)
$$



end)

Maximum stress in the cantilever beam (at the supported

$$
\alpha=\mathrm{F}^{*} \mathrm{~L} /(\mathrm{I} / \mathrm{v})
$$

Moment of inertia (of a rectangle):

$$
\mathrm{I}=\mathrm{b} * \mathrm{~h} \wedge 3 / 12
$$

TABLE I. EQUATION SYMBOLS

\begin{tabular}{|l|c|c|}
\hline \multicolumn{1}{|c|}{ symbol } & characteristic & units \\
\hline E & Young's Modulus & $\mathrm{MPa}$ \\
\hline I & Moment of Inertia & $\mathrm{mm} 4$ \\
\hline W & Force & $\mathrm{N}$ \\
\hline$\alpha$ & Bending stress & $\mathrm{MPa}$ \\
\hline y & Deflection & $\mathrm{mm}$ \\
\hline L & Length of beam & $\mathrm{mm}$ \\
\hline v & Distance to neutral fiber & $\mathrm{mm}$ \\
\hline b & Width of beam & $\mathrm{mm}$ \\
\hline h & Height of beam & $\mathrm{mm}$ \\
\hline
\end{tabular}

With a known length (L), moment of inertia (I) and force (W), Young's modulus can easily be calculated.

Care should be taken for the correct dimensions in the setup. a $1 \%$ error on dimensions (width of the beams) will yield a $5 \%$ error on measured values. In the remote experiment we will take different materials with distinct differences in properties to compensate the inaccuracy of the setup.

Even with careful construction of the experiment, students should be well aware about the spread on their results. Since results are collected "manually", the accuracy of the measurement is not very great.

\section{Construction of the experiment.}

The experiment is constructed to test 3 different materials. Two of the materials (steel S235JR, Al60xx) are known to the user, and in the experiment will be used to show the difference between material and shape stiffness. One material is unknown to the user, but properties can be calculated with the knowledge and measurements of the known materials. The unknown material can then be found in a table with material properties which is added in the theoretical section of the website.

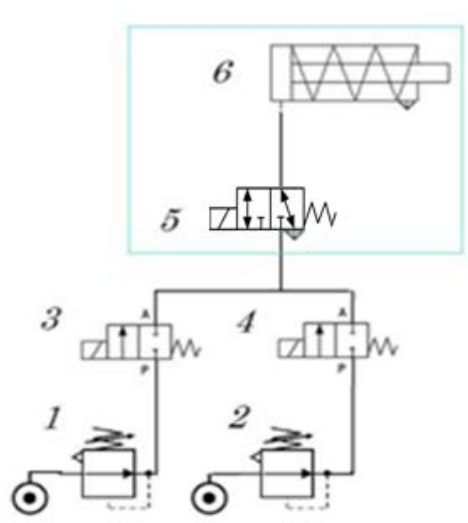

Figure 2 Pneumatic Control Scheme

1. Pressure control: $0.6 \mathrm{MPa}$

2. Pressure control $0.4 \mathrm{MPa}$

$3-4$ valves to select pressure, control from within webpage.

5. valve to control cylinder(s)

6 . cylinder for loading beams.

$5-6$ will be repeated for each set of beams of the same material.

The setup consists of 6 cantilever beams loaded with a known force. The cantilever beams are paired, with identical/similar dimensions (same area cross-section, but $90^{\circ}$ difference in orientation), and made of 3 different materials (2

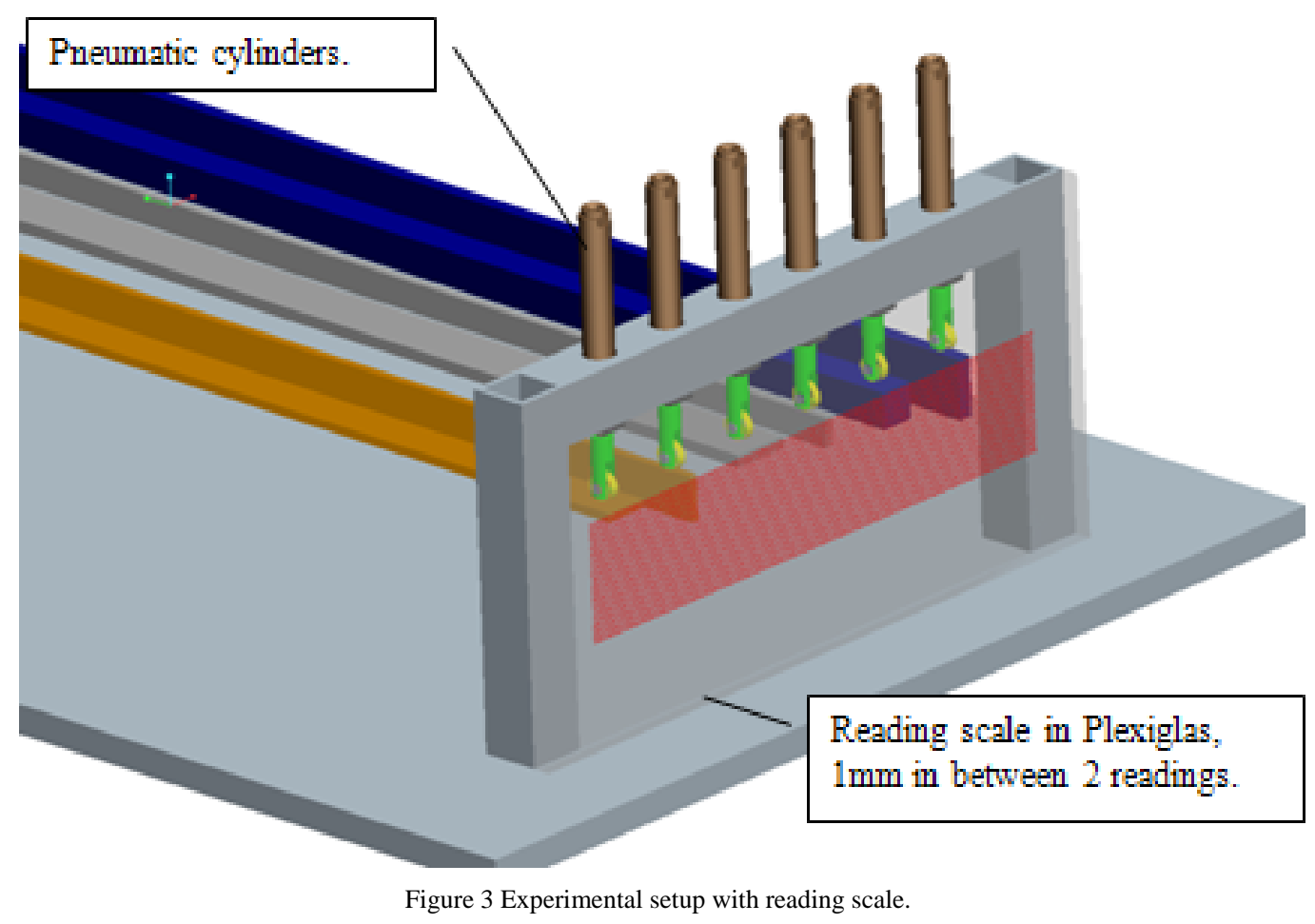


known and described materials, one to be determined by the student). The loading of each cantilever beam is done with a pneumatic cylinder. This gives the opportunity to also differentiate on the applied load (to evaluate other test settings, depending on the applied pressure (0.6 and $0.4 \mathrm{MPa})$. Pneumatic cylinders are reasonably cheap, small, and use compressed air as an energy medium, which is clean and safe to use. The cylinders in use will be FESTO EG6-25, with a piston diameter of $6 \mathrm{~mm}$, and a stroke of $25 \mathrm{~mm}$. They deliver a loading force of $12 \mathrm{~N}$ at a pressure of $0.6 \mathrm{MPa}$. The pneumatic control scheme of the experiment setup is described in figure 3 . Pressure will be set after testing to

The selection of forces will be controlled in the web interface and selection will be per material group in the experimental setup. As such, the 2 readings (one for every orientation of the beam) will be available for one (out of three) materials in the same experiment.

This will give following results for the selected materials (with a length of $400 \mathrm{~mm}$ and a loading force of $12 \mathrm{~N}$ ):

TABLE II. MATERIALS AND BEAM DIMENSIONS

\begin{tabular}{|l|l|c|l|l|l|l|}
\hline Material & $\begin{array}{l}\text { Young's } \\
\text { Modulus }\end{array}$ & $\begin{array}{c}\text { Beam } \\
\text { height }\end{array}$ & $\begin{array}{c}\text { Beam } \\
\text { Width }\end{array}$ & $\begin{array}{c}\text { Deflection } \\
\text { at } \text { end }\end{array}$ & $\alpha$ & $\begin{array}{c}\text { M } \alpha \xi \\
\alpha\end{array}$ \\
\hline & $\mathbf{M P a}$ & $\mathbf{m m}$ & $\mathbf{m m}$ & $\mathbf{m m}$ & $\mathbf{M P a}$ & $\mathbf{M P a}$ \\
\hline $\begin{array}{l}\text { Steel } \\
\text { S235JR }\end{array}$ & 210000 & 15 & 3 & 0.36 & 43 & 235 \\
\hline $\begin{array}{l}\text { Steel } \\
\text { S235JR }\end{array}$ & 210000 & 3 & 15 & 9 & 213 & 235 \\
\hline Al60xx & 70000 & 10 & 3 & 3.7 & 96 & $>100$ \\
\hline Al60xx & 70000 & 4 & 20 & 9 & 90 & $>100$ \\
\hline NYLON & 3200 & 20 & 5 & 6 & 14.5 & 50 \\
\hline NYLON & 3200 & 12 & 12 & 12 & 17 & 50 \\
\hline
\end{tabular}

With the formulas on deflection and cross section properties, it is easy to calculate area cross section properties (shape stiffness). Also Young's modulus of the material (material stiffness) can be calculated. With the results of the known materials, the properties of the unknown material can be calculated, and then found in a comparison table in the theoretical explanation section on the experiment website. The formulas are presented on screen, for offline calculation. Formulas for deflection, maximum bending stress, calculation of the moment of inertia will be presented. Also a material selection table with a number of identifiable materials will be included, to find out about the unknown material(s).

Choice was made not to put an automated calculation module on the website, to stimulate the student to use formulas, and to accurately use the (numerical) data provided in the experiment and their measured results.[4] One of the important competences students need in calculations is the use of units, and an automated calculation would take over the responsibility of the student over the correct use of units and the formula.
The webpage will also contain a number of explanation pages on the theory of strength of materials. This section will have to be studied first by the students. The experimental part will contain the 6 cantilever beams, loaded by a pneumatic cylinder (different force loading conditions possible). Measuring the deflection could be done with camera pictures on a graded background, or with inductive of capacitive sensors. In our setup, measurement of the deflection will be done on a visual scale (figure 4). As such the experiment is visually attractive to the user. The results are presented on the screen through the use of simple webcams, which make the computer setup very easy. This method is a tradeoff between simple (low resolution measuring) and attractive versus correct but complex measurement.

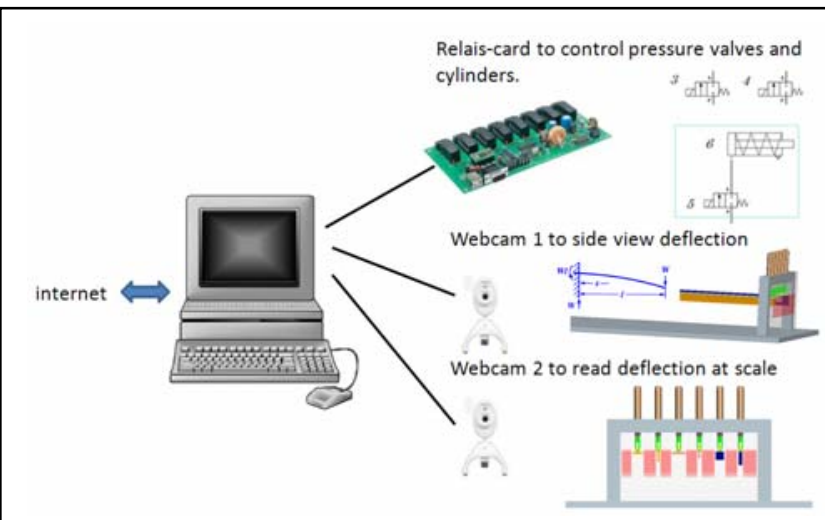

Figure 4 Experiment computer link layout.

Linking to the computer is done with an 8 channel relaiscard which can be connected to the serial port (DB9 or USB) of the computer.

The web page layout should be appealing to students and easy to use. On the other hand, it should contain all theoretical information so that students can understand the experiment and are able to absorb the matter. By keeping it simple, we will not divert the attention of the user away from the experiment. The webpage will contain following sections:

- Introduction: (on strength of materials in engineering)

- Theoretical background: (on shape and material stiffness)

- Setup of the experiment: (explanation on the construction of the experiment.)

- Assignment: (what tasks should students perform during and after the experiment.)

- Manual for the use of the experiment ( how to run the experiment.)

- $\quad$ (Run the) experiment: (control the remote laboratory and make the necessary measurements.)

- $\quad$ Answers (answer and explanation for self control)

Since the purpose of the experiment is to additionally explain to students the difference between shape and material stiffness, and not to substitute any formal learning, we do not need any evaluation section on the remote laboratory. We will 
however procure to the user a section containing the answers and some additional information on the use Young's modulus acquired through different testing setups. (Young's modulus tested in a bending experiment or the same modulus from a tension test can be different due to coincidences. ) With this answering section, the remote laboratory can be autonomously used.

Eventually a section for communication (forum) could be added, if there is decided to use the experiment as a compulsory part of the strength of materials course, so that students can discuss their findings and possible differences in results.

\section{CONCLUSION.}

Not every physical phenomenon can be put in a remote lab, but for many standard experiments, meant to instruct basic knowledge, the remote experiment offers a suitable solution. For more complex experiments, an interactive demonstration laboratory is a better choice.

The construction of the remote laboratory on material versus shape stiffness will enable students to experiment on specific properties of materials. The experiment can be repeated at any time. It is more cost and time efficient (24/7) than a physical laboratory or interactive demonstration laboratory setup.

In the experiment choice is made explicitly not to automate calculation, to stimulate students to reflect on their readings, accuracy, units and the use of formulas, to stimulate their learning.

The web pages with the experiment explaining the setup and presenting the theoretical back-ground of the experiment will prepare students effectively to conduct the experiment. Students with a learning through experience approach will benefit from the fact that they can conduct real experiments. It will also provide all the required knowledge on the matter, even without conducting the experiment. This is essential for students with a learning style engaging in abstract analysis of the problem.

\section{REFERENCES}

[1] B. D. Moulton, V. L. Lasky \& S. J. Murray, "The development of a remote laboratory: educational issues", World Transactions on Engineering and Technology Education vol.3, No.1, 2004

[2] C. Colwell, E. Scanlon, M. Cooper, "Using remote laboratories to extend access to science and engineering”, Computers \& Education vol.38, 2002, p. 65-76,

[3] E. Fabregas, G. Farias, S. Dormido-Canto, S. Dormido, F. Esquembre, "Developing a remote laboratory for engineering education", Computers \& Education vol 57,2011 , p. 1686-1697,

[4] ABET (2004). Criteria for Accrediting Engineering Programs. ABET Engineering Accreditation Commission. Retrieved from the World Wide Web: http://www.abet.org/Linked\%20DocumentsUPDATE/Criteria\%20and\%20PP/05-06-EAC\%20Criteria.pdf. 